\title{
The effect of ultra low-frequency brain stimulation on the kindling effect in rats
}

\author{
JOHN GAITO \\ York University, Downsview, Ontario M3J 1P3, Canada
}

\begin{abstract}
An experiment was conducted with rats to evaluate the effect of various low frequencies of brain stimulation on kindling behavior induced by $60-\mathrm{Hz}$ sine-wave stimulation. The effective threshold intensity (ETI) to elicit altered behavior was determined on four separate occasions, with 5 days of daily trials between determinations. On each day, experimental rats were stimulated with current of a specific frequency on the first and third trials and with $60-\mathrm{Hz}$ current on the second trial. There were four experimental groups, one each for $1-, .1-, .01-$, and $.001-\mathrm{Hz}$ stimulation. A fifth group received no stimulation on Trials 1 and 3 and $60-\mathrm{Hz}$ current on Trial 2. Suppression of altered behavior induced by the $60-\mathrm{Hz}$ stimulation trial was present for all ETI determinations with the four experimental groups; the mean threshold increased on each successive determination. Suppression was greatest for the $.1, .01$, and .001 groups. Grossly, it appears that the interference effect gradually increases with decreasing frequency.
\end{abstract}

The "kindling effect" has been investigated in a number of laboratories (e.g., Gaito, 1976b; Goddard, McIntyre, \& Leech, 1969; Racine, 1972; Wada \& Sato, 1975). In rats this effect involves a change from normal exploration (State 1), to behavioral automatisms (Stage 2: chewing, eye closure on ipsilateral side, salivation), and finally, to clonic convulsions (Stage 3) in response to electrical stimulation of a specific brain site (e.g., amygdala). During Stage 3, the rat stands on its hind paws and bilateral convulsions of the forelimbs occur. A kindling progression occurs also in other animals, namely, frogs, reptiles, mice, rabbits, cats, monkeys, and baboons (Racine, 1978). A permanent change that does not damage tissue is assumed to occur in the brain during kindling (Goddard et al., 1969; Racine, 1978). Behavioral, chemical, electrophysiological, and neurological aspects of this effect have been investigated by many researchers (Gaito, 1976a; Racine, 1978).

In a series of experiments, it was found that $1-\mathrm{Hz}$ or $3-\mathrm{Hz}$ sine-wave stimulation before and after a $60-\mathrm{Hz}$ stimulation trial suppressed the tendency of the $60-\mathrm{Hz}$ current to produce kindling behavior (Gaito, 1979a, 1979b; Gaito, 1980a, 1980b, 1980c, 1980d; Gaito, Nobrega, \& Gaito, 1980). The experiments with $3 \cdot \mathrm{Hz}$ stimulation were conducted at an intertrial interval of $1 \mathrm{~h}$ between the imposition of the $3-\mathrm{Hz}$ and $60-\mathrm{Hz}$ stimulation trials. Other intertrial intervals have been used with the $1-\mathrm{Hz}$ agent. With 1 - and $3-\mathrm{h}$ intertrial intervals, the suppression effect was pronounced. The effect was present with a 24-h interval but was reduced greatly (Gaito \& Gaito, 1981); with a 72-h interval, the effect was almost lost (Gaito, Note 1). These results indicate that the $1-\mathrm{Hz}$ suppression process is time dependent, and they suggest the possibility that it may dissipate completely at longer time intervals.
The present experiment was undertaken to evaluate frequencies below $1 \mathrm{~Hz}$ (viz., .1, .01, and .001). Some of these frequencies, especially the last two, would appear to be almost DC in nature for the duration of stimulation used in our experiments, and DC current stimulation tends to produce lesions (Gaito, 1981). With these two frequencies, not a single complete sine wave would occur within the $60 \mathrm{sec}$ of stimulation (.6 and .06 of a sine-wave cycle, respectively).

\section{METHOD}

Fifty male Wistar rats (approximately 190-230 days of age) were implanted unilaterally in the amygdala with nichrome bipolar electrodes. The brain coordinates for electrode implantation were the same as in many experiments in our laboratory: $.5 \mathrm{~mm}$ posterior to bregma, $4.5 \mathrm{~mm}$ from midline, $8.5 \mathrm{~mm}$ from skull (Gaito, 1976b).

Stimulation was not imposed until at least 7 days after surgery. Then the 50 rats were stimulated with $60-\mathrm{Hz}$ sine waves for $30 \mathrm{sec}$ during three trials on the 1st day. One hour intervened between each trial. A Lafayette stimulator was used; the intensity was 100 microA (peak to peak). On the first trial of the 2nd day, the effective threshold intensity $\left(\mathrm{ETI}_{1}\right)$ was determined. The $60-\mathrm{Hz}$ current was increased until a Stage 2 or 3 response was elicited. Then 15 microA was added to allow for day-by-day threshold fluctuations. Two further trials of stimulation at this intensity were provided.

Then one group of 10 rats received stimulation with $1-\mathrm{Hz}$ sine waves for $60 \mathrm{sec}$ on Trials 1 and 3 each day for 5 days at twice the $\mathrm{ETI}_{1}$ value. A $60-\mathrm{Hz}$ stimulation trial was provided on Trial 2 for $30 \mathrm{sec}$ at $\mathrm{ETI}_{1}$ (Group 1, 1-60-1). There was $1 \mathrm{~h}$ between trials. The second, third, and fourth groups of rats were stimulated with $.1 \mathrm{~Hz}, .01-\mathrm{Hz}$, and $.001-\mathrm{Hz}$ current, respectively, for $60 \mathrm{sec}$ at double the $\mathrm{ETI}_{1}$ values on Trials 1 and 3 and with $60 \mathrm{~Hz}$ on Trial 2 for $30 \mathrm{sec}$ at ETI (Group 2, $.160-.1$; Group 3, .01-60-.01; Group 4, .001-60-.001). There were 10 rats in each group. Ten other rats received $60-\mathrm{Hz}$ stimulation on Trial 2, but on Trials 1 and 3 each rat was placed in the apparatus without stimulation (Group 5, X-60-X). All 
$60-\mathrm{Hz}$ stimulation on Trial 2 was at ETI for $30 \mathrm{sec}$, a duration that has been used routinely in our research. Stimulation on Trials 1 and 3 was for $60 \mathrm{sec}$ duration; this duration has been found to produce a drastic suppressive effect in previous experiments. The intensity of stimulation with any frequency never exceeded 560 microA on these or later trials.

Following this 5-day period, rats from all groups had $\mathrm{ETI}_{2}$ determined over six trials during 2 days (three trials per day). Then another block of 5 days of stimulation occurred in which each group was treated in the same fashion as during the 5-day block of trials prior to the $\mathrm{ETI}_{2}$ determination. This alternation of ETI determinations and a 5-day block of trials was continued through the ETI ${ }_{4}$ determination. Then all rats were rested for 18 days and $\mathrm{ETI}_{5}$ was determined on one trial.

At the end of most previous experiments, histological analyses had been performed on all rats. However, no gross lesions had been detected at intensities of 560 microA and below (intensities that are used routinely in our experiments). The tissue around the electrode tips of rats stimulated with $1-\mathrm{Hz}$ or $1-\mathrm{Hz}$ and $60-\mathrm{Hz}$ current was indistinguishable from that of rats stimulated only with $60-\mathrm{Hz}$ current. Histological analyses were conducted in the present experiment with three rats from each of the five groups. Each animal was sacrificed with an overdose of sodium pentobarbital and perfused with saline and formalin. The brains were extracted and placed in a $10 \%$ formalin solution. Each brain was frozen, and 50-micron sections were mounted on microscopic slides; these slides were placed in a photographic enlarger and used to obtain information concerning electrode site and the presence or absence of lesions around electrode tips. The enlargement was approximately tenfold. A Luxo magnifier with a lens that provided approximately double enlargement was mounted over the microtome so that the electrode tips and the electrode track could be observed during the obtaining of each tissue section. The use of this continuous viewing of the tissue greatly increased the efficiency of the histological analy sis.

\section{RESULTS}

The electrode tips for the 15 rats used in the histological analyses were in the amygdala or an adjacent structure in all cases. The tissue around the electrode tips for the 1-60-1 groups was indistinguishable from those in the $\mathrm{X}-60-\mathrm{X}$ group; there were no obvious gross lesions for either of these groups. However, the tissue around electrode tips was not as clearly free of tissue damage suggesting possible lesions, in one or more of the rats in each of the other groups.

The rats subjected to $1-, .1-, .01-$, and $.001-\mathrm{Hz}$ sinewave current did not show the usual kindling progression. No Stage 2 or 3 behavior occurred, as was the case in previous research with 1 - and $3-\mathrm{Hz}$ stimulation.

Two dependent variables, ETI and composite score, have been sensitive to the effects of $1-\mathrm{Hz}$ and $3-\mathrm{Hz}$ effects in previous experiments and were used in the present experiment. The latter measure involves a score of 1 for Stage 1 behavior, 2 for a Stage 2 response, and 3 for a clonic convulsion. The ETI results are shown in Table 1. As in previous experiments, the control rats, those subjected to no stimulation on Trials 1 and 3 (X-60-X group), showed a gradual decrease over the four determinations. The 1-60-1 group had the gradual increments over ETI determinations that have been typical
Table 1

Mean ETI Values (in Microamperes) and Recovery Rate (RR) for the Five Groups of 10 Rats

\begin{tabular}{lrrrrrr}
\hline & \multicolumn{6}{c}{ ETI Determination } \\
\cline { 2 - 6 } \multicolumn{1}{c}{ Group } & 1 & 2 & 3 & 4 & 5 & RR \\
\hline X-60-X & 354 & 286 & 251 & 223 & 184 & 100 \\
$1-60-1$ & 305 & 436 & $475^{*}$ & $541^{* *}$ & 275 & 70 \\
$.60-.1$ & 314 & 496 & $585 \dagger$ & $0 \dagger \dagger$ & 407 & 40 \\
$.01-60-.01$ & 294 & 570 & $585 \ddagger$ & $0 \dagger \dagger$ & 556 & 0 \\
$.001-60-.001$ & 273 & 568 & $545 \dagger$ & $543 \ddagger \ddagger$ & 467 & 10 \\
\hline
\end{tabular}

Note-A few rats showed only Stage 1 response during some ETI determinations and were not used for later aspects, except for $E_{T I}$. Recovery rate refers to the percentage of rats that convulsed on $E_{5 T}$ at approximately the previous low ETI determination value. $\quad *_{n}=8 . \quad *_{n}^{*}=7 . \quad t_{n}=5 . \quad t_{n}=0$. $\ddagger n=3$. $\quad \neq \neq n=2$.

of rats stimulated with $1-\mathrm{Hz}$ or $3 \cdot \mathrm{Hz}$ sine waves in previous experiments. The increments for the other three groups were greater, especially from $\mathrm{ETI}_{1}$ to $\mathrm{ETI}_{2}$ determinations. The changes from $\mathrm{ETI}_{1}$ to $\mathrm{ETI}_{2}$ determinations for the X-60-X, 1-60-1, .1-60-.1, $.01-60-.01$, and $.001-60-.001$ groups were $-68,+131$, +182 , +276 , and +295 microA, respectively. These values suggest an increasing suppression effect from $1-\mathrm{Hz}$ to $.001-\mathrm{Hz}$ stimulation.

A number of rats showed Stage 1 behavior for later ETI determinations and were not used thereafter until the $\mathrm{ETI}_{5}$ determination. In the 1-60-1 group, this event occurred with two rats for $\mathrm{ETI}_{3}$ determination and for a third rat on $\mathrm{ETI}_{4}$. Five rats had Stage 1 responses for $\mathrm{ETI}_{3}$ in the $.1-60-.1$ group; all 10 rats showed this behavior for the ETI 4 determination. In the .01-60-.01 group, 7 and 10 rats had Stage 1 responses during the $\mathrm{ETI}_{3}$ and $\mathrm{ETI}_{4}$ determinations, respectively. Five and eight rats in the $.001-60-.001$ group showed this behavior for these determinations, respectively. For this Stage 1 behavior, an ETI value of 585 microA was assigned to that rat. (Twenty-five was added to the upper limit of 560 microA.)

The $\mathrm{ETI}_{3}$ and $\mathrm{ETI}_{4}$ values are not reliable ones for the $.1-60-.1, .01-60-.01$, and $.001-60-.001$ groups, because of the small numbers involved. Furthermore, the values of 585 microA for rats showing Stage 1 behavior at the $\mathrm{ETI}_{3}$ or $\mathrm{ETI}_{4}$ determinations are probably underestimations. One would expect, for example, that the increment from $\mathrm{ETI}_{2}$ to $\mathrm{ETI}_{3}$, or $\mathrm{ETI}_{3}$ to $\mathrm{ETI}_{4}$, would be at least as great as that from $\mathrm{ETI}_{1}$ to $\mathrm{ETI}_{2}$. For these groups and the latter transitions, the increment is 182 and greater. Many of the rats involved in the $\mathrm{ETI}_{3}$ determination showed Stage 1 behavior and received a value of 585 microA (viz., all five rats in the .1-60-.1 and $.01-60-.01$ groups and three of five rats in the $.001-60-.001$ group), thus tending to reduce the possible increment from $\mathrm{ETI}_{2}$ to $\mathrm{ETI}_{3}$.

The mean composite score over three blocks of trials also showed the suppression effect (Table 2). The mini- 
Table 2

Mean Composite Score

\begin{tabular}{lrrr}
\hline & \multicolumn{3}{c}{ Trial Block } \\
\cline { 2 - 4 } \multicolumn{1}{c}{ Group } & \multicolumn{1}{c}{1} & \multicolumn{1}{c}{2} & \multicolumn{1}{c}{3} \\
\hline X-60-X & 11.0 & 14.6 & 15.0 \\
$1-60-1$ & 8.6 & 9.2 & 9.0 \\
$.1-60-.1$ & 6.8 & 6.3 & 5.7 \\
$.01-60-.01$ & 5.8 & 5.9 & 5.9 \\
$.001-60-.001$ & 5.8 & 7.8 & 7.0 \\
\hline
\end{tabular}

mum and maximum scores, respectively, for composite score over five trials are 5 and 15. Each rat receives a score of 1 for Stage 1 behavior, a score of 2 for Stage 2 responses, and a value of 3 for each convulsion. The $\mathrm{X}-60-\mathrm{X}$ group had the usual kindling progression over the three blocks of trials, with all rats showing Stage 3 behavior during Block 3. The 1-60-1 group had mean composite scores that were at the boundary of Stages 1 and 2 and did not show a kindling progression. The other three groups had even lower mean scores.

The control group (X-60-X) was the only one that remained stable or showed an increase in mean composite score over the five trials in each of the three blocks. All other groups evidenced an interference effect, especially during the later trials. The effect was least for the 1-60-1 group and greatest with the other groups.

The mean value for the five trials was at the beginning of Stage 2 during Block 1 and at the convulsion stage for the other blocks with the X-60-X group. The 1-60-1 group had a value indicating behavior just prior to and during early Stage 2 . The other groups have means that indicated pre-Stage 2 behavior in each of the three blocks of trials. By Block 3 , no rats were available in the $.1-60-.1$ and $.01-60-.01$ groups because Stage 1 behavior resulted during the $\mathrm{ETI}_{3}$ determination. Similar results occurred with 8 of the 10 rats in the $.001-60-.001$ group.

The $\mathrm{ETI}_{5}$ determination showed definite recovery from the suppression or interference for most rats in the 1-60-1 group (Table 1). A 70\% recovery rate was observed; seven rats were at or below the lowest ETI $\left(\mathrm{ETI}_{1}\right)$, and three were above this point. Thus, this group showed almost complete recovery. The .1-60-.1 group had partial recovery with a $40 \%$ rate. The $.01-60-.01$ and $.001-60-.001$ groups had rates of $0 \%$ and $10 \%$, respectively. The $\mathrm{ETI}_{5}$ values for the X-60-X group was lower than any of the previous determinations, as has been the case in previous experiments.

The mean value for the $\mathrm{ETI}_{5}$ determination showed this same pattern. The mean for the 1-60-1 group on this determination was well below that of the previous low ETI point $\left(\mathrm{ETI}_{1}\right)$, whereas the means for the other groups stimulated. with low-frequency current were well above the ETI value. The discrepancy between the $\mathrm{ETI}_{1}$ and $\mathrm{ETI}_{5}$ determinations was greatest for the $.01-60-.01$ group. For this group. little change occurred in the mean from $\mathrm{ETI}_{2}$ to $\mathrm{ETI}_{5}$, because the $\mathrm{ETI}_{2}$ mean was almost at the upper limit. 585 microA. The
X-60-X group, obviously, had the usual decline in mean value from $\mathrm{ETI}_{1}$ to $\mathrm{ETI}_{5}$.

\section{DISCUSSION}

The responses of the rats in the low-frequency groups at intensities at or below 560 microA were similar to those previously observed with $1-$ and $3-\mathrm{Hz}$ stimulation relative to kindling aspects. Kindling progression occurred for the $\mathrm{X}-60-\mathrm{X}$ rats. Rats stimulated with $1-, .1-, .01-$, and $.001-\mathrm{Hz}$ sine waves showed only Stage 1 behavior in response to these frequencies.

In previous research, an interference or suppression effect was obtained on Trial 2 stimulation by $60-\mathrm{Hz}$ current when stimulation on Trials 1 and 3 was by $60-, 30-, 10-, 5-$, and $1-\mathrm{Hz}$ current, but not for the nonstimulated rats ( $\mathrm{X}-60-\mathrm{X}$ group) (Gaito, 1980c). The average differences in ETI determinations for the nonstimulated and 60-, 30-, 10-, 5-, and 1- $\mathrm{Hz}$ groups were $-46.3,-16.0,-1.3,+51.3,+87.3$, and +97.0 micro $A$, respectively. The present results could be added. However, because some of the groups had few rats present for $\mathrm{ETI}_{3}$ and $\mathrm{ETI}_{4}$ determinations, the mean differences over all determinations would not produce a meaningful result. But the difference between ETI ${ }_{1}$ and $\mathrm{ETI}_{2}$ could be useful. For the X-60-X, $1-60-1, .1-60-.1, .01-60-.01$, and $.001-60-.001$ groups, these values were $-68,+131,+182,+276$, and +295 microA, respectively.. Overall there appears to be increasing degrees of suppression as one goes from $60-\mathrm{Hz}$ to $.001-\mathrm{Hz}$ stimulation; the degree of suppression varies with remoteness from the $60-\mathrm{Hz}$ condition.

The present experiment indicates that the suppression effect previously uncovered in this laboratory with $1-\mathrm{Hz}$ and $3-\mathrm{Hz}$ stimulation can be obtained with other frequencies as well. The greatest degree of suppression occurs with the frequencies below $1 \mathrm{~Hz}$. The $1-\mathrm{Hz}$ stimulation produces a lesser degree of suppression, but a pronounced amount.

The exact basis for the suppression effect is not known. With frequencies of $1 \mathrm{~Hz}$ and above, it probably involves an inhibitory process that is generated during the brain stimulation (McIntyre \& Goddard, 1973; Mucha \& Pinel, 1977; Racine, 1978). It appears to be a transient event inasmuch as many affected rats will convulse at previous low threshold levels after a 15- to 18-day rest (Gaito, 1980a) (as in the present experiment, a $70 \%$ recovery rate for the $1-\mathrm{Hz}$ stimulated rats after an 18-day rest) or a 32-day rest (Gaito, 1981), and a 24 - or $72 \mathrm{~h}$ intertrial interval allows for much of the effect to dissipate (Gaito \& Gaito, 1981; Gaito, Note 1). This transient event may be similar to the transient interference (aftereffect) reported by McIntyre and Goddard (1973). These short-term events are in sharp contrast to the kindling process, which is relatively permanent (Goddard et al., 1969; Racine, 1978).

Tissue damage may be involved for the $.1-, .01-$, and $.001-\mathrm{Hz}$ sine waves, as suggested by the histological analyses and the low recovery rates. It is possible that tissue damage may be involved in the $1-\mathrm{Hz}$ stimulation condition also. However, this aspect does not appear to be the case, according to the histological analyses and the almost complete recovery rates. Furthermore, the frequencies of $.1, .01$, and $.001 \mathrm{~Hz}$ are 10,100 , and 1,000 times less than the $1-\mathrm{Hz}$ sine waves. Thus, they are very different from the $1-\mathrm{Hz}$ stimulation condition, from a physical viewpoint. Within the $60 \mathrm{sec}$ stimulation condition used in our experiments, they appear to be similar to DC stimulation, which does produce tissue damage. This similarity is especially pronounced for the $.01-$ and $.001-\mathrm{Hz}$ stimulation conditions. Within this $60 \mathrm{sec}$ period of stimulation, .6 and .06 of a complete sinewave cycle. respectively, are produced in the brain of a rat. Because of the possible similarity of very low frequencies to DC stimulation. frequencies below $1 \mathrm{~Hz}$ will not be used to investigate the suppression effect in the future. 


\section{REFERENCE NOTE}

1. Gaito, J. Research in progress, 1982.

\section{REFERENCES}

Gatro, J. The kindling effect as a model of epilepsy. Psychological Bulletin, 1976, 83, 1097-1109. (a)

GaITo, J. An oscillation effect during sequential alternations of unilateral amygdaloid stimulations within the kindling paradigm. Physiological Psychology, 1976, 4, 303-306. (b)

GaIto, J. Suppression of $60-\mathrm{Hz}$ induced convulsive behavior by 3-Hz brain stimulation. Bulletin of the Psychonomic Society, 1979, 13, 223-226. (a)

Gaito, J. 3-Hz brain stimulation interferes with various aspects of the kindling effect. Bulletin of the Psychonomic Society, 1979, 13, 67-70. (b)

Gaito, J. The effect of variable duration one hertz interference on kindling. Canadian Journal of Neurological Sciences, 1980, 7, 59-64. (a)

GaIto, J. The effect of varying durations of stimulation on the 3-Hz interference effect. Bulletin of the Psychonomic Society, 1980, 15, 221-214. (b)

GaIto, J. Gradient of interference by various frequencies on $60-\mathrm{Hz}$ kindled behavior. Canadian Journal of Neurological Sciences, 1980, 7, 223-226. (c)

GaITo, J. Interference effects within the kindling paradigm. Physiological Psychology, 1980, 8, 120-125. (d)
Gaito, J. The effect of low frequency and direct current stimulation on the kindling phenomenon in rats. Canadian Journal of Neurological Sciences, 1981, 8, 249-253.

Gaito, J., \& Gaito, S. T. The effect of several intertrial intervals on the $1-\mathrm{Hz}$ interference effect. Canadian Journal of Neurological Sciences, 1981, 8, 61-65.

Gaito, J., Nobrega, J. N., \& Gaito, S. T. Interference effect of $3-\mathrm{Hz}$ brain stimulation on kindling behavior induced by 60-Hz stimulation. Epilepsia, 1980, 21, 73-84.

Goddard, G. V., McIntyre, D. C., \& Leech, C. K. A permanent change in brain function resulting from daily electrical stimulation. Experimental Neurology, 1969, 25, 295-330.

McIntyre, D. C., \& Goddard, G. V. Transfer, interference and spontaneous recovery of convulsions kindled from the rat amygdala. Electroencephalography and Clinical Neurophysiology, 1973, 35, 533-543.

Mucha, R. F., \& Pine L, J. P. J. Postseizure inhibition of kindled seizure. Experimental Neurology, 1977, 54, 266-282.

RACINE, R. J. Modification of seizure activity by electrical stimulation: 1. After-discharge threshold. Electroencephaloggraphy and Clinical Neurophysiology, 1972, 32, 269-279.

RAcine, R. Kindling: The first decade. Neurosurgery, 1978, 3, 234-252.

WadA, J. A., \& Sato, M. The generalized convulsive seizure state induced by daily electrical stimulation of the amygdala in split brain cats. Epilepsia, 1975, 16, 417-430.

(Received for publication January 11, 1982.) 